\title{
Assessment of urban planning concepts for the development of post-industrial cities
}

\author{
Maria Grishina ${ }^{1 *}$ [0000-0001-8234-8403], Yulia Medyanik ${ }^{1}$ [0000-0001-8230-8452], Elena Rakhmatullina ${ }^{1}$ \\ [0000-0002-2368-9694], Elena Matveeva ${ }^{1}$ [0000-0001-9507-4405], and Khayrullina Albina ${ }^{1}$ \\ ${ }^{1}$ Kazan State University of Architecture and Engineering, 420043, Zelenayast., Kazan, Russia
}

\begin{abstract}
This article is devoted to an overview study of the implemented concepts of the development of modern post-industrial cities. In the study of the issue of the feasibility of the implemented concepts, many domestic and foreign publications on the research topic are given. The authors of this article made an attempt to predict the possible results of the realization of the implemented concepts of the development of post-industrial cities in the long term of their development. The chosen goal is achieved by solving the following tasks:

- to compare the strategies of urban development being implemented;

- to identify the signs of an industrial and post-industrial city;

- identify the strengths and weaknesses of the concepts;

- describe the positive and negative consequences after the implementation of the concepts of sustainable development of post-industrial cities.

Keywords: Urban development, conceptual design, post-industrial city, «strategy 2030», «smart city», eco-city, natural landscape, sustainable development, landscape resources.
\end{abstract}

\section{Introduction}

In modern scientific research, the authors examine different aspects of urban development. For example, Göran Terborn focused on the influence of the globalization of today's politics and economy on the formation of modern concepts of urban planning. He formulated three aspects. These aspects define the iconography of post-industrial cities. This is the verticality of urbanization, the desire for innovation and exclusivity. Göran Terborn, in his forecasts, considers two ways of urban development: re-corporation and globalization [1].

Balashov presents the concept of «smart city» development as a result of a joint equilateral dialogue between investors, municipal authorities and citizens. The author outlined the main drawback of the new concept «Strategy 2030». This disadvantage lies in the use of the principles and mechanisms of urban development from the past era of industrialization. The historical aspect of cities is also ambiguous, because in the «Strategy 2030» its role is limited only to the architectural heritage. Balashov states that the main advantage of the Strategy 2030 concept is the creation of councils for urban planning, economic and architectural heritage preservation instead of numerous expert communities.

${ }^{*}$ Corresponding author: peaceofthepease@gmail.com 
But the author believes that the councils being formed will not be sufficiently consolidated in solving the problems of urban development [2].

E. Titov in his article «Urban co-management: concept and modern research» focuses on the reform of urban municipalities and the introduction of a cluster management system $[3]$.

The authors of the article on the concept of an eco-city for Russia rely on Abel Wolman's model of urban metabolism. They compare Wolman's concept with the eco-city concept. The authors of the article present the concept of an eco-city as a reflection on the rapid development of the consumer society in the post-industrial period. His publication notes that the paradigm of an eco-city should develop in parallel in three directions: social, economic and environmental. For an eco-city in Russia, the authors propose: a model of «environmentally sustainable development»; improvement of mechanisms for monitoring the effectiveness of the work of municipal authorities, ecological landscape and construction expertise; restriction of the number of storeys in urban development; greening of transport infrastructure [4, 5].

Articles about the rational use of landscape resources in the concepts of sustainable development of post-industrial cities in Russia have received great relevance. The importance of using the resources of the natural landscape in the formation of a healthy psychological and intellectual urban environment is noted [6]. Modern articles often discuss the possibilities of using the landscape approach in post-industrial cities. B. Kochurov notes in his article that the urban landscape is built on the basis of the existing natural landscape. This means that the sustainable development of post-industrial cities and settlements depends on taking into account the planning resources of the natural landscape, the historical context, economic opportunities and the technical level of the implementation of the concept of sustainable development [7].

Many researchers note in their publications a close relationship between sustainable planning of urban systems and the economic feasibility of using landscape resources. One of the basic principles of sustainable urban development is the economics of land use and cadastre. There are studies on international methods for assessing and systematizing existing concepts of urban development $[8,9]$. For example, E. Popov and K. Semyachkov propose a methodology for assessing urban planning concepts in four areas. These are sustainability, connectivity, innovation and social level [10,11].

Of interest from foreign studies are publications related to the results of the analysis of the «Smart City» concepts. These studies examined the features of urban planning in developing countries, the transitional formats of conceptual models of urban planning, the role of urban communities in determining the development strategy [12, 13, 14]. Of particular interest is the use of the principles of modern urban planning and mechanisms of interaction between the urban community, municipal authorities and the interdisciplinary professional community $[15,16,17]$. In foreign studies, it is important today to study the economic efficiency of the possibilities of exploiting renewable energy sources $[18,19]$.

\section{Materials and methods}

Based on the results of the review of publications on the selected topic, three leading concepts of the development of modern cities can be distinguished.

The first is the general global concept «Strategy 2030». About Russia. This concept of sustainable urban development prioritizes the economic component, a comfortable urban environment and the role of «social demand» in the municipal management of urban areas.

The second is the eco-city concept. About the landscape resource. Rule in three directions is social, ecological and economic. 
The third is the «Smart City» development concept. About technology. The economic feasibility of this concept lies in the massive automation of production and the full use of renewable energy sources. However, the flaw in this concept lies in the dependence of automation and robotics on energy and high cyber-reliability of software.

So why does this article only cover concepts of post-industrial cities? First of all, this is due to the fact that today we all live in post-industrial cities. It is undeniable that the development of every settlement today is still based on the production of something. And in our cities, there is a whole complex of signs of an industrial city. A universal approach and typical methods and techniques that are used in urban planning. The development of the administrative districts of the city depends on the stability of the economy of the industrial center of this district. Massive urbanization of territories that were previously considered unsuitable for use. This process made possible a rapid increase in the urban population while ensuring the comfort of urban spaces. Another positive aspect of industrial urbanization is the developed transport infrastructure as a fundamental component of the city's development. The advent of public high-speed transport significantly saves time resources and reduces transport communications between spacious locations in different parts of the city. This initially positive urbanization process ultimately led to mixed consequences. For example, such a phenomenon as mass standard construction made it a priority to provide all citizens with individual housing. It turned out to be a humane decision, but to the detriment of the emotional-psychological and cultural-intellectual level of the created urban environment. In industrial cities, a positive experience has been gained in the implementation of a systematic approach in the creation of urban «green» spaces. But the methods used for landscaping and maintaining parks, squares, boulevards and embankments are, in the end, controversially positive. The dubious economies of socialist cities reflected a contradictory low level of use of landscape resources in urban planning. Sometimes one gets the impression that the paradigm «We do it because we can do it» prevailed in the landscape construction of socialist industrial cities.

Another disadvantage of industrial cities is the problem of energy resources. This is due to the high level of energy intensity, energy consumption of cities. This leads to the dependence of the energy structure on fossil and nuclear fuels [5, 16].

Ultimate methods in urban planning management are one of the most powerful constraints on urban development.

Before identifying the signs of a post-industrial city, let us note that this is a transitional form in the evolution of urban planning objects. This statement is justified by the fact that it is common for transitional forms to combine the features of several forms at the same time. For example, in the studied urban planning concepts of urban development, the signs of an industrial city are absent or no longer have fundamental significance. At the same time, in the borderline form of «post-industrial city»development, the key growth factors remain dependence on production and transport infrastructure. But in the prospect of coming to the post-industrial stage, the focus in urban planning should shift. Because, in a post-industrial city, the main factors of sustainable development are the energy efficiency of urban infrastructures, the ecological stability of the urban landscape and the transition from an industrial economy to a high-tech economy.

Thus, all cities that are described in the considered concepts have the characteristics of a post-industrial city. The formation of these characteristics in post-industrial cities occurs due to certain changes. The basic driving force for the transition of industrial cities to postindustrial ones are urban planning processes, which are aimed at changing the development paradigm.

The technological development process contributes to:

- the availability of various technical capabilities to the broad masses of communities, 
- acceleration of data exchange when performing complex multifunctional operations in the management of current urban planning processes. This will help bring the maintenance and development of urban areas to a qualitatively new level.

- increasing the possibilities of remote control and automatic processing of analytical data sets $[2,8,10,19]$.

The process of urban energy efficiency growth affects:

- updating the use of alternative energy sources;

- increasing the profitability of the use of renewable fuels;

- formation of the priority of the most profitable use of natural landscape resources from the point of view of ecology, economy and comfortable environment.

Changing the global scenario of life and revising the resources of time in the life of each person entails fundamental changes in all urban planning infrastructures:

- already today, the development of digitalization and automation in the areas of management, production and service allows many operations to be performed remotely and around the clock without the influence of the human factor. The growth of these opportunities will determine the fundamental changes in terms of logistics and transport. The transport infrastructure will change qualitatively;

- development of resource-saving technologies «gray water»for electricity production by urban buildings $[17,18,19]$;

- the introduction of mechanisms for alternative management of the city's development consolidates the adoption of functional planning decisions on the territory of the city. This process will increase the flexibility of sustainable management of the city's development. For example, the transition from considering the identity of cities as a set of locations with architectural monuments to the integrated accumulation and preservation of architectural experience in an endlessly changing urban landscape.

Based on the assessment systems of the planning concepts for the development of postindustrial cities, several general criteria can be distinguished.

Environmental friendliness and efficiency of using urban areas and infrastructures $[6,7$, $13,16]$. This criterion for assessing the sustainable development of post-industrial cities consists in the balance of consumption and reproduction of energy resources. Obviously, this criterion is of the greatest importance in the eco-city concept. But the economic aspect of sustainable development matters in Strategy 2030 and in the Smart City. However, in the concept of a smart city, the main role is assigned to technologies, which today remain very energy-intensive and unreliable in terms of cyber defense.

The criterion of the identity of cities is especially important for the development of national centers in the era of globalization $[1,8]$. This criterion is the strong point of the Russian concept «Strategy 2030». This strategy includes the creation of a professional community that will be responsible for solving the problem of identifying, studying and augmenting the architectural heritage as accumulated experience in the material environment of post-industrial cities. The priorities of the eco-city concept also include an alternative solution to the problem of cities' identity. It is assumed that the competent use of natural landscape resources will ensure the uniqueness and iconography of post-industrial cities. The concept of a smart city is the epitome of the city of the era of globalization and puts the functionality of the urban landscape above its uniqueness.

The strongest side of the «Smart City» concept is such criteria as exclusivity and verticality. This is predictable in the paradigm of unlimited technology development. Exclusivity in this context implies the social division of society according to the levels of technology availability. For example, today the service for disabling advertising content is a paid service. The criterion of verticality is associated with the exclusivity and compaction of the building. For example, the compactness of the placement of capital construction projects today is an archeological task in urban planning. The 2030 strategy also takes into 
account the development of these criteria. But the idea of the implementation of the ecocity concept becomes impossible. For example, it is not entirely clear how the transport infrastructure will develop without the possibility of reducing pedestrian connections and transport communications by compacting capital construction projects by increasing their number of storeys.

The alternative or flexibility of urban areas is one of the leading factors in the sustainable development of post-industrial cities. The main indicator of this factor is the level of involvement and interaction of the municipality, investors, professional and public communities in the management of the city $[3,19]$. This criterion is the strong point of all the considered concepts of sustainable development of post-industrial cities [20].

\section{Results}

The signs of an industrial city in Russia are

- decentralization of city districts based on an autonomous industrial center;

- the paradigm of conquering the natural landscape, rather than using its resources for the purpose of urbanization;

- a typical model of the functional planning organization of the city;

- centralized management system for urban development;

The signs of a post-industrial city in Russia can be called:

- penetration of technologies into all areas of citizens' life;

- transition from energy-intensive to energy-efficient cities;

- a change in the paradigm of citizens' life.

Each concept described in this article has advantages and disadvantages. Each concept has a certain flexibility in the variability of the choice of the city's development path. It should be assumed that, like the "Garden City» concept at the beginning of the 20th century, none of the existing urban development concepts will be fully implemented. But in the end, we will get cities that include features of several concepts at the same time. For the sustainable development of post-industrial cities, the balance of history and innovation, pragmatic economy and emotional and architectural perception, natural landscape and technological comfort is important[21,22].

The results of the assessment of the sustainable development of a post-industrial city are shown below. The diagram reflects the relative equivalence of the considered concepts. But according to individual criteria, the advantages of a particular concept of sustainable development are clearly visible (Fig 1).

\begin{tabular}{|c|c|c|}
\hline \multicolumn{3}{|c|}{$\begin{array}{l}\text { sustainable urban } \\
\text { development concepts }\end{array}$} \\
\hline strategy - 2030 & eco city & smart city \\
\hline ecology & ecology & ecology \\
\hline identity & identity & identity \\
\hline exclusivity & exclusivity & exclusivity \\
\hline alternative & alternative & alternative \\
\hline
\end{tabular}

Fig. 1. Assessment of the concept of sustainable urban development.

\section{Discussion and conclusion}

The relevance of an objective assessment of urban planning concepts of post-industrial cities is confirmed by the need for a more detailed study of the experience of the industrial 
period. The need to increase experience requires an objective assessment of the successful and unsuccessful results of the development of industrial cities[21]. This will help to avoid the repetition of unsuccessful results and the search for successful solutions to urban planning problems. In addition, identifying the cause-and-effect relationships of unsuccessful decisions will allow you to form a reasonable and logical roadmap for decisions.

\section{References}

1. I. A. Vershinin. Representation of power in the urban space: the concept of GöranTerborn, Vestnik Peoples' Friendship University of Russia. Series: Sociology, 18, 2, 226-237 (2018)

2. A. I. Balashov, A. G. Sanin,Strategic guidelines for the development of St. Petersburg: contradictions between the declared values and practices of urban management, Journal of Social Policy Research, 14, 2, 197-212 (2016)

3. A. A. Voloshinskaya, V. M. Komarov, Eco-City Concepts: Recommendations for Russia, Terra Economicus, 15, 4, 92-108 (2017)

4. E. A. Titov, Concept and Contemporary Research Issues of State and Municipal,Urban Co-Governance 1, 173-194 (2021)

5. Yu. M. Grishaeva, O. Yu. Matantseva, I. V. Spirin, M. I. Savosina, Z. N. Tkacheva, D. V. Vasin,Sustainable development of transport in Russian cities: experience and urgent tasks, South of Russia: ecology, development,4, 24-46 (2018)

6. E. P. Petrashen, V. S. Speranskaya, A. O. Kuzmina, Destructive landscapes in the context of urban public space. Problems of rehabilitation, adaptation and integration, Vestnik St. Petersburg University. Art Criticism,8, 4, 693-714 (2018).

7. B. Kochurov, Yu. A. Khaziakhmetova, I. V. Ivashkina, E. A. Sukmanova, Landscape approach in urban planning, South of Russia: ecology, development, 3, 71-82 (2018)

8. O. V. Razumova, The concept of sustainable development of a modern city during the reconstruction of buildings of the first mass series, Bulletin of the Transnistrian State Academy of Budgeting and Architecture,2, 101-107 (2017)

9. E. V. Popov, K. A. Semyachkov, Systematization of approaches to assessing the development of smart cities, Economy of the region, 16, 1, 14-27 (2020)

10. L. A. Joia, A. Kuhl, Smart City for Development: A Conceptual Model for Developing Countries, Lecture Notes in Computer Science, 203-214 (2019). DOI 10.1007/978-3030-19115-3_17

11. A. C. Neuroni, S. Haller, W. Winden, V. Carabias-Hütter. O. Yildirim, Public Value Creation in a Smart City Context: An Analysis Framework, Setting Foundations for the Creation of Public Value in Smart Cities,282, $49-76$ (2019) DOI: 10.1007/978-3-31998953-2_3

12. K. Paskaleva, I. Cooper,Innovations in Co-Created Smart City Services, Setting Foundations for the Creation of Public Value in Smart Cities,282, 165-195 (2019) DOI: 10.1007/978-3-319-98953-2_7

13. S.E. Bibri, Transitioning from Smart Cities to Smarter Cities: The Future Potential of ICT of Pervasive Computing for Advancing Environmental Sustainability, Smart Sustainable Cities of the Future, 660, 535-599 (2018) DOI: 10.1007/978-3-319-73981$6 \_10$

14. P. Cardullo, R. Kitchin, Being a «citizen» in the smart city: up and down the scaffold of smart citizen participation in Dublin, Ireland, GeoJournal, 84, 1, 1-13 (2018) DOI 10.1007 / s10708-018-9845-8 
15. E. Okwechime, P. Duncan, D. Edgar,Big data and smart cities: a public sector organizational learning perspective. Information Systems and e-Business Management 16, 3, 601-625 (2018) DOI 10.1007/s10257-017-0344-0

16. D. Y. Sardana, Conducting Business in China and India Palgrave Macmillan Asian Business, Zhu Institutional Environment.Series. London: Palgrave Macmillan,291, 85155 (2017) DOI 10.1057/978-1- 137-54721-7_4

17. J. S. Engel, J. Berbegal-Mirabent, J. M. Piqué,The renaissance of the city as a cluster of innovation. Cogent Business \& Management, 5, 1, 1-20 (2018) DOI 10.1080/23311975.2018.1532777

18. R. Webb, X. Bai, M. S. Smith, R. Costanza, D. Griggs, M. Moglia, G. Thomson, Sustainable urban systems: Co-design and framing for transformation, 47, 1, 57-77 (2017) DOI 10.1007 / s13280-017-0934-6

19. R. Wlodarczyk-Marciniak, D. Sikorska, K. Krause, Awareness of residents about the role of informal green spaces in a post-industrial city with an emphasis on regulatory services and the potential for urban adaptation, Sustainable cities and society, 59, 102$236(2020)$

20. J. Zakirova, S. Khusnutdinova, The problems of formation and conservation of the green frame (green carcass) of the satellite city (on the example of Zelenodolsk), Kazan State University of Architecture and Engineering,Kazan Federal University, Kazan RF (2018)

21. M. Grishina, Article Testing the Methods of Reconstruction of the Spatial Solution of the Pedestrian Street, IOP Conf. Series: Materials Science and Engineering, 753, 042069 (2020) DOI: 10.1088/1757- 899X/753/4/042069

22. M. P. Grishina, A. T. Khamidullina, Urban tasks of development of modern rural settlements on the example of the lower condition (Republic of Tatarstan, Russia) Izvestia KGASU, 54, 4, 134-143 (2020) 